\title{
Examining Communication and Patient Recall in a Family Medicine Residency
}

Christopher Ebberwein, Ph.D., ${ }^{1,2}$, Nikki Keene Woods, Ph.D., M.P.H. ${ }^{2}$, Holly Allen Terrell, M.D. ${ }^{1,2}$, Mary Boyce, M.D. ${ }^{1,2}$, Jared Reyes, M.Ed. ${ }^{2}$, Amy Chesser, Ph.D. ${ }^{2}$

${ }^{1}$ Wesley Family Medicine Residency Program, Wichita, KS

${ }^{2}$ University of Kansas School of Medicine-Wichita

Department of Family and Community Medicine

\begin{abstract}
Background. Understanding key aspects of effective physician-patient communication could benefit residency education and improve patient comprehension of health information. Discrepancies between what physicians say and what patients understand can reduce quality of care (e.g., patient adherence and satisfaction), making it imperative to know when gaps in patient understanding exist. The objective of this study was to identify residents' efforts to assess patient understanding and the degree to which patients recalled information and instructions provided in the medical encounter.

Methods. Residents and patients were observed in routine medical encounters in a Midwestern family medicine residency center. Patients were surveyed immediately following the encounter for recall of information and recommendations from the encounter, satisfaction with physician communication, and health literacy.

Results. A total of 21 physician-patient encounters were observed. An inverse relationship was noted (Spearman's rho $=-0.43, \mathrm{~N}=21, \mathrm{p}=0.05$ ) between number of topics discussed during the encounter and the percentage of information recalled.

Conclusions. Patient recall was related inversely to the number of topics covered by resident physicians. These results challenge physicians and medical educators to study and employ further those elements of physician-patient communication that enhance patient recall and understanding.
\end{abstract}

KS J Med 2013; 6(1):1-10.

\section{Introduction}

The Accreditation Council for Graduate Medical Education (ACGME) has identified effective physician-patient communication as central to the medical encounter, and includes "interpersonal and communication skills” as a core competency for residency education. ${ }^{1}$ Physicians are expected to practice communication that results in the effective exchange of information and collaboration with patients. Effective communication between the physician and patient is associated with improved patient satisfaction and adherence. ${ }^{2}$ A number of authors reinforce the need to enhance communication skills in the clinical training of physicians to mitigate problems such as physician use of medical terminology, ${ }^{3,4}$ low patient understanding, ${ }^{5}$ health disparities, ${ }^{6}$ hospital readmissions, ${ }^{2,7}$ and willingness to comply with recommendations following a hospitalization. ${ }^{2}$

Discrepancies have been found between what physicians say and what patients understand, ${ }^{8}$ suggesting efforts are needed to enhance and verify patient understanding and recall. Such discrepancies are thought to result from a combination of factors including physician use of medical jargon and patient health literacy. ${ }^{3,9}$ When physicians use medical jargon without 
clarifying the information within a context that patients understand, patients are less likely to comprehend information, such as health status, lab values, and disease management options. ${ }^{4}$

Additional barriers to patient comprehension are present when patients have low health literacy. Functional health literacy has been defined as the "measure of a person's capacity to function in the health care setting as determined by literacy (comprehension of written health care materials) and numeracy (ability to understand and act on numerical health care instructions)."10 Some of the problems associated with poor health literacy include incorrect medication usage, awareness of need for follow-up testing, and understanding of treatment side-effects. ${ }^{3}$ Physicians need to assess patient understanding during each clinical encounter to ensure patients comprehend and can recall important health information.

Accurate patient recall has been studied with standardized patients, with an emphasis on "recall promoting behaviors" that physicians can use in practice, including ways of verifying understanding. ${ }^{11}$ Yet, such "assessments of understanding" (AUs) can themselves be effective or ineffective based on the depth of response they encourage from the patient. ${ }^{12,13}$ Farrell and colleagues ${ }^{12}$ demonstrated a vast majority of AUs were hampered by such limitations as close-ended question format (e.g., “OK?”; “Any questions?") and/or failing to pause for patient response. The authors concluded that the attempts made by residents to assess understanding point to a need for feedback about how to be effective. For example, asking patients to restate recommendations from an encounter appeared to aid recall in primary care settings. ${ }^{14}$

As part of a Behavioral Science/Family Systems Educator Fellowship project for the Society of Teachers of Family Medicine, this pilot study sought to identify residents' efforts to assess patient understanding and the degree to which patients recalled information and instructions provided in the medical encounter. Additionally, patient health literacy and patient assessment of physician communication were collected to investigate possible conditions that might affect understanding and recall.

\section{Methods}

Participants. As a pilot study to understand physician-patient communication further, the study included a convenience sample $(\mathrm{N}=21)$ of patients presenting for care at a Midwestern family medicine residency program. The study was approved by two local Institutional Review Boards. Inclusion criteria required that patients were 18 years or older, possessing adequate knowledge of English, with ability to provide informed consent, and who had a previous diagnosis of diabetes, hypertension, asthma, or depression. These conditions were selected because they represent common conditions treated by family physicians. Each participant received a \$15 gift card.

A list of patients meeting the study criteria, with a scheduled appointment, was generated through the electronic medical record on a daily basis. Front desk staff was given a list of eligible patients at the beginning of each day, and those patients were provided an information sheet regarding the study upon check-in. A member of the study team was present in the waiting room to obtain informed consent prior to each clinical encounter. Post Graduate Year (PGY) 2 and PGY 3 resident physicians were recruited as primary care providers for the study $(\mathrm{N}=9)$.

Physician communication measures. The ACGME emphasizes "interpersonal and communication skills" as a core competency for resident physician training. ${ }^{1}$ A variety of 
communication training strategies exist across family medicine residencies, including use of checklists, direct observation, standardized patients, and as is true in this residency, video review that assesses and critiques the effectiveness of communication of residents in their interactions with regular clinic patients. ${ }^{15}$ For this study, physician-patient encounters were video recorded to observe and analyze physician communication. The video files were transcribed and investigators categorized and counted the types of information delivered to patients (e.g., providing information or advice), the types of recommendations they made for continued care (e.g., prescription medication, lifestyle change, referral to a specialist), instructions for follow-up, and attempts made to assess patient understanding. For example, the physician statement, "Verapamil may bring your BP down" would constitute an informational statement about medication. The statement, "Make sure you don't wipe it (medication) in your eyes or ears or anything" would be coded as an advice statement about medication. Follow-up statements refer to physician directions to the patient regarding future appointments, testing, or consultations/ referrals.

Assessments of understanding (AU) were coded based on the four types described by Farrell and Kuruvill ${ }^{13}$ in a study of pediatric residents' counseling on newborn genetic screening. They included: teach-back, open-ended questions, closeended questions, and “OK?" questions. Inter-observer agreement (IOA) was obtained among four independent raters (i.e., minimum of $80 \%$ agreement on codes) prior to coding and IOA was checked on $25 \%$ of the transcript analysis to ensure the agreement between raters. Each transcript was reviewed by two independent raters to summarize topical themes and communication categories.

Patient recall and satisfaction. Recall data were collected immediately following the patient encounter through a brief exit interview. Patients were asked to describe what the physician explained or wanted them to understand during the visit and what the physician asked them to do as a result of the visit. Each item recalled by the patient was compared to the transcript from that encounter. Only those items recalled by the patient that matched information provided by the physician were counted as recalled information. The total number and type of statements recalled by patients was compared to the total number and type of information provided by the physician during the encounter to quantify patient recall of information.

To understand the rate of patient recall in comparison to patient satisfaction with physician communication, patients were asked to complete the Communication Assessment Tool (CAT) ${ }^{16}$ following the exit interview. The CAT is a 15-item, five-point rating scale ( $1=$ poor, $5=$ excellent $)$, assessing patients' perceptions of the physician's communication skills during the encounter. Consistent with previous use of the CAT in resident communication, ${ }^{16}$ one item about staff treatment of patients was omitted in analysis.

Patient health literacy data were collected through the short form of the Test of Functional Health Literacy in Adults (STOFHLA), ${ }^{17,18}$ a 36-item measure in which participants fill in missing words from four multiple choice items while reading passages on healthcare.

Data analysis. To assess the level of patient recall from the exit interviews, resident communication during the encounters was coded as: information (e.g., regular exercise is an important component 
of healthy living), advice (e.g., you should exercise 3-5 times per week for 30 minutes or more), or follow-up (e.g., we will need to recheck your blood pressure in one-week). Information and advice were designated further based on the content (e.g., blood sugars).

Nonparametric statistical tests were used, as normal distribution within the data set could not be assumed. A Mann-Whitney $\mathrm{U}$ test examined statistically significant differences in the proportion of information recalled when residents employed no AUs versus the use of one or more AUs. The total number of topics discussed during encounters was split by frequency into three subsets. The range for each subset was decided based on cut points for three equal independent groups. A Kruskal-Wallis test compared median encounter times and recall rates associated with each subset. The pvalues were reported for each test. Spearman's rho correlation assessed relationships between the number of topics discussed and patient recall rates. Correlation data were reported as Spearman's rho and p-value. For all statistical tests, a p-value less than or equal to 0.05 was considered significant.

Health literacy (STOFHLA) scores were divided into three categories: inadequate health literacy (0 to 16 inclusive), marginal health literacy (17 to 22 inclusive), and adequate health literacy (23 to 36 inclusive). ${ }^{17}$ Patient communication satisfaction (CAT questionnaire) data were analyzed by the mean score for each question and the frequency of ratings categorized as excellent. ${ }^{16}$ Quantitative data were analyzed using Predictive Analytics Software (v.18.0, Chicago, Illinois; formerly SPSS).

\section{Results}

The majority of participants were nonHispanic Caucasians ( $\mathrm{n}=12,57 \%)$ and female ( $n=15,71 \%)$. The age range was from 27 to 77 years and the average age of respondents was $51.7(\mathrm{SD}=15.8$; Table 1$)$.

Table 1. Demographic information for participants $(\mathrm{N}=21)$.

\begin{tabular}{|r|c|}
\hline & Frequency (\%) \\
\hline Fender & \\
\hline Fale & $6(29 \%)$ \\
\hline Race Caucasian & $12(57 \%)$ \\
\hline African American & $9(43 \%)$ \\
\hline Other & $2(10 \%)$ \\
\hline Age Group & \\
\hline$\leq 30$ years old & $2(9 \%)$ \\
\hline $31-40$ years old & $5(24 \%)$ \\
\hline $41-50$ years old & $1(5 \%)$ \\
\hline $51+$ years old & $13(62 \%)$ \\
\hline
\end{tabular}

${ }^{a}$ Individuals who identified with more than one race.

Patient encounters. The mean time for each encounter was 16.86 minutes $(\mathrm{SD}=$ 6.76) ranging from 3.87 to 34.03 minutes in length. At least one $\mathrm{AU}$ was used during $52 \%(\mathrm{n}=11)$ of the resident-patient encounters. Only two types of AU (“OK?”, close-ended) were used during the encounters. The median number of topics discussed per encounter was seven, and the median numbers of information, advice, and follow-up given were five, two and one, respectively. The mean patient recall rates for information, advice, and follow-up were $53 \%(\mathrm{n}=20), 57 \%(\mathrm{n}=16)$, and $66 \%(\mathrm{n}=$ $18)$, respectively. The mean recall rate $(\mathrm{N}=$ 21) was calculated as $53 \%$. The median patient recall rate among resident physicians who used no AUs was $47 \%$ and for those residents who use one or more AUs median patient recall was 58\% ( $\mathrm{U}=-0.65, \mathrm{p}=0.51)$. Additionally, no statistically significant differences ( $U=0.56, p=1.0$ ) were found in the mean length of the encounters and 
number of AUs (No AU vs. One or More AU).

The total number of topics presented during each encounter (range from 4 -19) was divided into three subsets; less than 7 topics $(\mathrm{n}=9), 7-11$ topics $(\mathrm{n}=6)$, and greater than 11 topics $(n=6)$. These subsets were used to compare mean differences in encounter time and proportion of topics patients recalled during the follow-up interview. No statistically significant differences in duration of encounter $\left[\chi^{2}(2, N\right.$ $=21)=5.48, \mathrm{p}=0.06$ ] occurred between groups.

A Kruskal-Wallis test comparing median patient recall rates associated with each subset of topics revealed no significant differences between groups $\left[\chi^{2}(2, \mathrm{~N}=21)=\right.$ 3.99, $\mathrm{p}=0.14]$. Patients recalled a greater percentage of information when less than seven topics were discussed (60\%) compared to $41 \%$ when more than 11 topics were discussed (Table 2). A scatterplot graph showed a trend for patient recall rates compared to number of topics discussed (Figure 1). An inverse relationship was noted (Spearman's rho $=-0.43, \mathrm{~N}=21, \mathrm{p}=$ 0.05 ) between number of topics discussed during a patient encounter and the percentage of information recalled.

Table 2. Summary of recall rates for the number of topics discussed.

\begin{tabular}{|r|c|c|}
\hline Number of Topics Discussed & Range & $\begin{array}{c}\text { Patient Recall Rate } \\
\text { (Median Number of Recalled Topics) }\end{array}$ \\
\hline$<7$ Topics discussed $(\mathrm{n}=9)$ & $4-6$ & $60 \%(3.0)$ \\
\hline $7-11$ Topics discussed $(\mathrm{n}=6)$ & $7-11$ & $55 \%(4.5)$ \\
\hline$>11$ Topics discussed $(\mathrm{n}=6)$ & $12-19$ & $41 \%(5.0)$ \\
\hline
\end{tabular}

${ }^{*}\left[\chi^{2}(2, \mathrm{~N}=21)=3.99, \mathrm{p}=0.14\right]$

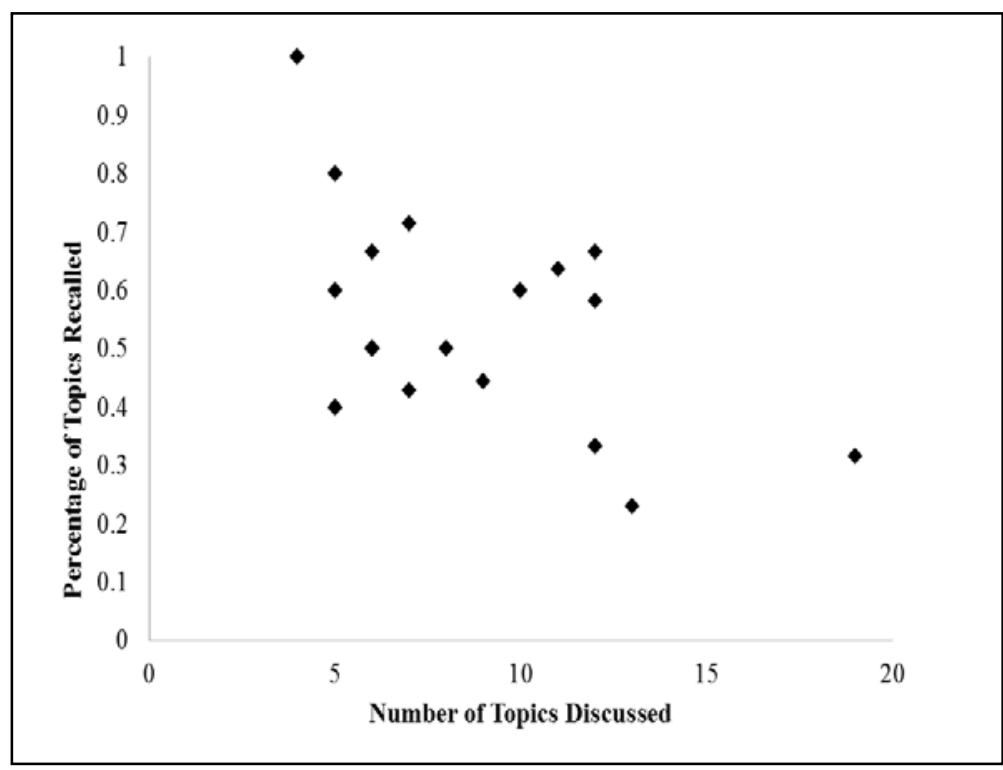

Figure 1. Relationship between number of topics discussed and patient recall. (Spearman's rho = $-0.43, \mathrm{~N}=21, \mathrm{p}=0.05$ ) 
All statements on the CAT were rated as excellent by over $60 \%$ of the respondents ( $\mathrm{N}$ = 21; Table 3). The overall mean percent for "excellent" was $87 \%$ (SD $=0.24)$, and the overall mean score for the CAT was 4.82 $(\mathrm{SD}=0.41)$. Items rated most frequently as excellent were "Dr. treated me with respect" (95\%), “Dr. paid attention to me" (95\%), and "Dr. gave me as much info as I wanted" (95\%). The item rated as excellent the least number of times was "Dr. checked to be sure I understood everything” (67\%).

Table 3. Summary of communication assessment tool responses ${ }^{\mathrm{a}}(\mathrm{N}=21)$.

\begin{tabular}{|l|c|c|c|c|}
\hline & \% Excellent & Mean & SD & Median \\
\hline $\begin{array}{l}\text { 1. Dr. greeted me in a way that made me feel } \\
\text { comfortable }\end{array}$ & 90 & 4.9 & 0.30 & 5 \\
\hline 2. Dr. treated me with respect & 95 & 4.9 & 0.44 & 5 \\
\hline 3. Dr. showed interest in my ideas about my health & 81 & 4.8 & 0.54 & 5 \\
\hline 4. Dr. understood my main health concerns & 86 & 4.8 & 0.51 & 5 \\
\hline 5. Dr. paid attention to me & 95 & 4.9 & 0.22 & 5 \\
\hline 6. Dr. let me talk without interruptions & 90 & 4.9 & 0.30 & 5 \\
\hline 7. Dr. gave me as much info as I wanted & 95 & 4.9 & 0.66 & 5 \\
\hline 8. Dr. talked in terms I could understand & 90 & 4.9 & 0.48 & 5 \\
\hline 9. Dr. checked to be sure I understood everything & 67 & 4.6 & 0.59 & 5 \\
\hline 10. Dr. encouraged me to ask questions & 81 & 4.7 & 0.64 & 5 \\
\hline 11. Dr. involved me in decisions as much as I wanted & 86 & 4.7 & 0.90 & 5 \\
\hline 12. Dr. discussed next steps, including any follow-up & 90 & 4.9 & 0.30 & 5 \\
\hline 13. Dr. showed care and concern & 46 & 0.51 & 5 \\
\hline 14. Dr. spent the right amount of time with me & 4.8 & 0.54 & 5 \\
\hline
\end{tabular}

${ }^{\mathrm{a}}$ Responses were in the form of a 5-point Likert scale ( 1 = poor, $5=$ excellent $)$.

The majority of participants had adequate health literacy $(n=19,91 \%)$, only two reported inadequate health literacy $(\mathrm{n}=$ 2, 9\%). Three individuals (14\%) did not complete the test within the prescribed seven-minute time limit, however, according to test instructions, their health literacy level was calculated and included in the results. No significant difference in health literacy among different races or genders was found (Fisher's exact test, p-values were 0.49 and 0.07 , respectively). 


\section{Discussion}

A substantial portion of information delivered during the patient encounters was lost immediately following the visit. Observed patient recall was 53\%. Previous research reported an average patient recall range from $48-90 \% .^{14,19-21}$

Residents addressed a large number of topics during the observed clinical encounters, a practice that might have limited patient recall. ${ }^{14}$ Even when a topic was covered briefly (e.g., your blood pressure today is 180), the overall quantity of information seemed to prohibit immediate patient recall. For example, one patient for whom more than 11 topics were addressed stated, "[The doctor] wants me to discontinue some medicines. I hope I'll get some paperwork on that because I don't remember which ones." The amount of information was related inversely to patient recall, which declined as the number of topics covered increased. However, the total number of recalled information increased as the number of topics covered increased.

The amount of information that a patient can recall may be limited by a ceiling effect. $^{22}$ This finding may suggest limiting the number of topics covered in appointments with the intent to improve patient recall, and is consistent with previous findings. ${ }^{14}$ Such a conclusion poses a challenge for physicians in the current healthcare atmosphere whereby patients are encouraged to list all their complaints and questions ahead of a visit. An alternative might be to increase aids to understanding, an idea consistent with research by Farrell et al. ${ }^{12}$ that the accumulation of data between each AU may be as indicative of recall rate as the total amount of information.

Residents in this study used zero AUs in $48 \%$ of the visits. When utilized, only those types of AUs the literature noted to be the least effective ${ }^{8}$ (i.e., close-ended questions and “OK?" questions) were included. The minimal use of AUs and the use of "lower quality” AUs did not significantly improve patient recall. Given these results, it is noteworthy that the fewest "Excellent" ratings $(67 \%)$ on the physician communication assessment tool occurred on the item, "Dr. checked to be sure I understood everything”.

Scores from the STOFHLA denoted the majority of participants as having adequate health literacy. This finding is not supported by the current literature on health literacy since the underserved population in a residency practice often shares characteristics with those most at-risk for low health literacy, such as low income and low education levels. ${ }^{23}$ It is possible that the tool is not sensitive enough to detect the literacy levels of this specific sub-group. Another possible explanation was that patients with adequate health literacy "self-selected" into the study. If that is the case, the recall rate in the follow-up interview is potentially even more telling, assuming greater health literacy would result in greater recall. ${ }^{24}$

Limitations. Discussion of these results must be framed within several limitations. This study was conducted with a small sample of patients and upper level residents at only one Midwestern residency. The convenience sample was not distributed equally among the nine residents, but was assigned based on resident availability in the family medicine center. These factors greatly limit the generalizability of results.

Secondly, patient recall was measured strictly according to self-report and by multiple researchers. Although written instructions were given to researchers for the sake of consistency, differences were noted in the time spent and the degree to which researchers persisted for recall information with patients. Recall data were collected immediately after the visit. Additionally, no effort was made in the analysis to determine 
the level of importance given by residents to one type of information over another. All information, advice, and follow-up topics were counted equally. Assuming physicians emphasize some data more than others, this type of review could have been useful to determine whether patients recall information differently based on a different level of emphasis.

Future studies of this kind would benefit from random assignment of patients equally across residents, increased sample size and resident participation, and the use of educational videotaping sessions of physician-patient encounters as a source of research data so as to increase efficiency.

Strengths. Multidisciplinary collaboration (i.e., medical school researchers, family medicine faculty, resident physicians, behavioral scientist, and medical students) allowed for a rich diversity of perspectives throughout the process, including the understanding of results. Previous studies with residents' use of AUs were conducted with standardized patients. ${ }^{13}$ This practicebased study allowed for examination of use of AUs during regular medical encounters between residents and their patients. While the study by Farrell et al. ${ }^{12}$ noted a smaller proportion of encounters in which no AU was used (21\% vs. 48\%), standardized patients were trained not to give any non-

\section{References}

${ }^{1}$ Robins L, Witteborn S, Miner L, Mauksch L, Edwards K, Brock D. Identifying transparency in physician communication. Patient Educ Couns 2011; 83(1):73-79. PMID: 20538421.

${ }^{2}$ Kripalani S, Jacobson TA, Mugalla IC, Cawthon CR, Niesner KJ, Vaccarino V. Health literacy and the quality of physician-patient communication during hospitalization. J Hosp Med 2010; 5(5):269-275. PMID: 20533572. verbal clues indicating a level of understanding. Such cues could make a difference in residents' use of AUs. This difference underscores the importance of evaluating resident-patient communication during clinical practice. Efforts should be made to observe resident-patient communication as a teaching strategy for improving resident communication skills.

\section{Conclusion}

This study emphasized the importance of studying, teaching, and employing those elements of physician-patient communication that enhance patient recall and understanding. The results challenge resident physicians to ensure that patients leave understanding the pertinent information and recommendations offered during the visit, either by prioritizing the information covered in medical encounters or by ensuring effective use of AUs during the encounter, or ideally by employing both. Future studies should assess resident use of AUs and other recall promoting behaviors (e.g., handouts, repetition, and patient restatement) following specific educational interventions to increase use of such behaviors. Measuring the impact of recall promoting behaviors on patient outcomes would strengthen the impact of such studies.

${ }^{3}$ Williams MV, Davis T, Parker RM, Weiss BD. The role of health literacy in patientphysician communication. Fam Med 2002; 34(5):383-389. PMID: 12038721.

${ }^{4}$ Castro CM, Wilson C, Wang F, Schillinger D. Babel babble: Physicians' use of unclarified medical jargon with patients. Am J Health Behav 2007; 31(Suppl 1):S85-95. PMID: 17931142.

${ }^{5}$ Weiss B. Health Literacy and Patient Safety: Help Patients Understand. 2nd 
Edition. Chicago, IL: American Medical Association Foundation, 2007.

${ }^{6}$ Barr DA. Health disparities in the United States: Social class, race, ethnicity, and health. Baltimore: Johns Hopkins University Press, 2008. ISBN: 0801888204.

7 Jencks SF, Williams MV, Coleman EA. Rehospitalizations among patients in the Medicare fee-for-service program. N Engl J Med 2009; 360(14):1418-1428. PMID: 19339721.

8 Jenkins V, Solis-Trapala I, Langridge C, Catt S, Talbot DC, Fallowfield LJ. What oncologists believe they said and what patients believe they heard: An analysis of phase I trial discussions. J Clin Oncol 2011; 29(1):61-68. PMID: 21098322.

${ }^{9}$ Bennett IM, Chen J, Soroui JS, White S. The contribution of health literacy to disparities in self-rated health status and preventive health behaviors in older adults. Ann Fam Med 2009; 7(3):204-211. PMID: 19433837.

${ }^{10}$ Schillinger D, Piette J, Grumbach K, et al. Closing the loop: Physician communication with diabetic patients who have low health literacy. Arch Intern Med 2003; 163(1):83-90. PMID: 12523921.

${ }^{11}$ Silberman J, Tentler A, Ramgopal R, Epstein RM. Recall-promoting physician behaviors in primary care. J Gen Intern Med 2008; 23(9):1487-1490. PMID: 18548316.

${ }^{12}$ Farrell MH, Kuruvilla P, Eskra KL, Christopher SA, Brienza RS. A method to quantify and compare clinicians' assessments of patient understanding during counseling of standardized patients. Patient Educ Couns 2009; 77(1):128-135. PMID: 19380210.

${ }^{13}$ Farrell MH, Kuruvilla P. Assessment of parental understanding by pediatric residents during counseling after newborn genetic screening. Arch Pediatr Adolesc Med 2008; 162(3):199-204. PMID: 1831 6655 .
${ }^{14}$ Bravo BN, Postigo JM, Segura LR, et al. Effect of the evaluation of recall on the rate of information recalled by patients in primary care. Patient Educ Couns 2010; 81(2):272-274. PMID: 20197226.

${ }^{15}$ Duffy FD, Gordon GH, Whelan G, et al. Assessing competence in communication and interpersonal skills: The Kalamazoo II report. Acad Med 2004; 79(6):495-507. PMID: 15165967.

${ }^{16}$ Myerholtz L, Simons L, Felix S, et al. Using the communication assessment tool in family medicine residency programs. Fam Med 2010; 42(8):567-573. PMID: 20830622.

${ }^{17}$ Baker DW, Williams MV, Parker RM, Gazmararian JA, Nurss J. Development of a brief test to measure functional health literacy. Patient Educ Couns 1999; 38(1): 33-42. PMID: 14528569.

${ }^{18}$ Wallace L, North American Primary Care Research Group. Patients' health literacy skills: The missing demographic variable in primary care research. Ann Fam Med 2006; 4(1):85-86. PMID: 16449402.

${ }^{19}$ Gabrijel S, Grize L, Helfenstein E, et al. Receiving the diagnosis of lung cancer: patient recall of information and satisfaction with physician communication. J Clin Oncol 2008; 26(2):297-302. PMID: 18182671.

${ }^{20}$ Stewart M, Meredith L, Brown JB, Galajda J. The influence of older patientphysician communication on health and health-related outcomes. Clin Geriatr Med 2000; 16(1):25-36, vii-viii. PMID: 10723 615.

${ }^{21}$ Falvo D, Tippy P. Communicating information to patients. Patient satisfaction and adherence as associated with resident skill. J Fam Pract 1988; 26(6):643-647. PMID: 3379367.

${ }^{22}$ Cowan N. The magical number 4 in shortterm memory: A reconsideration of mental storage capacity. Behav. Brain Sci 2001; 24(1):87-114. PMID: 11515286. 
${ }^{23}$ Ginde AA, Weiner SG, Pallin DJ, Camargo CA Jr. Multicenter study of limited health literacy in emergency department patients. Acad Emerg Med 2008; 15(6):577-580. PMID: 18616448.

${ }^{24}$ Smith SG, Wolf MS, von Wagner C. Socioeconomic status, statistical confidence, and patient-provider communica- tion: An analysis of the Health Information National Trends Survey (HINTS 2007). J Health Commun 2010; 15(Suppl 3):169-185. PMID: 21154092.

Keywords: physician-patient relations, communication barriers, health literacy, mental recall, graduate medical education 